\title{
Flying through congested airspaces: imaging of chronic rhinosinusitis
}

\author{
Davide Farina • Marco Ravanelli • Andrea Borghesi • \\ Roberto Maroldi
}

Received: 23 May 2010 /Revised: 31 May 2010 /Accepted: 2 June 2010 /Published online: 27 July 2010

(C) European Society of Radiology 2010

\begin{abstract}
The complex regional anatomy of the nose and paranasal sinuses makes the interpretation of imaging studies of these structures intimidating to many radiologists. This paper aims to provide a key to interpretation by presenting a simplified approach to the functional anatomy of the paranasal sinuses and their most common (and most relevant) variants. This knowledge is basic for the full understanding of chronic rhinosinusitis and its computed tomography (CT) patterns. As fungal infections may be observed in the setting of chronic rhinosinusitis, these are also discussed. Chronic sinus inflammation produces bone changes, clearly depicted on CT images. Finally, clues to suspecting neoplastic lesions underlying inflammatory sinus conditions are provided.
\end{abstract}

Keywords Paranasal sinuses $\cdot$ Sinusitis $\cdot$ Imaging

\section{Introduction}

Chronic rhinosinusitis is a common disease, causing high social and economic costs [1], and heavily impacting on the patient's quality of life [2]. Imaging of chronic rhinosinusitis is often regarded as a difficult task, particularly by young residents, probably because of the complexity of the anatomy that makes the search for the key to unravelling such a labyrinth of air cells (and its pathological features) a tough task. However, first impressions often lie: the anatomy can be quite easily understood if described from the perspective of function; likewise, imaging findings in

D. Farina $(\triangle) \cdot$ M. Ravanelli $\cdot$ A. Borghesi $\cdot$ R. Maroldi

Department of Radiology, University of Brescia,

Piazza Spedali Civili 1,

25123 Brescia, Italy

e-mail: nappaje@yahoo.it chronic rhinosinusitis can be quite clearly interpreted by radiologists when they have sufficient background on the functional anatomy. The purpose of this review is to offer a handful of basic concepts that may guide the inexperienced radiologist towards an easier approach to imaging of the paranasal sinuses in his or her daily routine.

Anatomy, stripped to the bone

Although the paranasal sinuses are a complex framework of air cavities, widely variable in number and size, their anatomy may be simplified using a schematic approach based on drainage pathways. In this perspective, two functionally distinct compartments can be identified: first, the anterior compartment - including the anterior ethmoid cells, the frontal and the maxillary sinus, draining into the middle meatus. Second, the posterior compartment - which is composed of the posterior ethmoid cells and the sphenoid sinus, draining into the superior meatus. The line of demarcation between the two compartments is the basal lamella of the middle turbinate, i.e. the attachment of the turbinate to the lateral nasal wall or medial orbital wall. Although the basal lamella can be seen on axial and coronal images, sagittal reconstructions, easily available on multislice computed tomography (MSCT) examinations, are best suited to precisely delineate its obliquely oriented course (Fig. 1).

For each of the aforementioned compartments some key anatomical landmarks can be defined. In the anterior one, all drainage pathways of the anterior ethmoid cells, and the frontal and maxillary sinus converge in an anatomical area located in the middle meatus; this is referred to as the ostiomeatal complex (Fig. 2). The ostiomeatal complex is composed of several structures: the uncinate process, a sickle-shaped bone structure projecting from the medial 


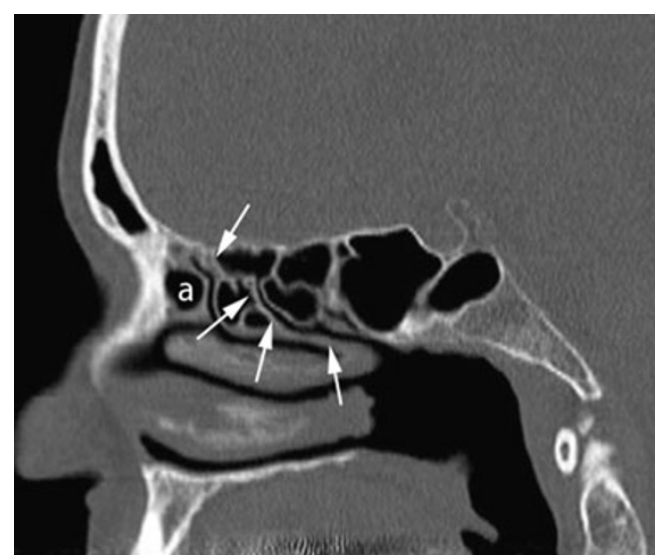

Fig. 1 Sagittal MPR reconstruction. Arrows outline the course of the basal lamella of the middle turbinate, which marks the border between anterior and posterior ethmoid air cells ( $a$ agger nasi cell)

maxillary sinus wall up to the skull base; the ethmoid bulla, generally the most prominent ethmoid air cell located above the uncinate process; the ethmoid infundibulum, the thin channel in between the uncinate process and the ethmoid bulla; the frontal recess, which is the obliquely orientated, funnel-shaped drainage pathway of the frontal sinus [3]. The anatomy of the frontal recess is closely related to that of the uncinate process: the medial and lateral borders of the frontal recess depend upon the superior attachment of the uncinate process. As described by Landsberg and Friedman [4] and Lee et al. [5], a cranial insertion of the uncinate process on the ethmoid fovea (the roof of the

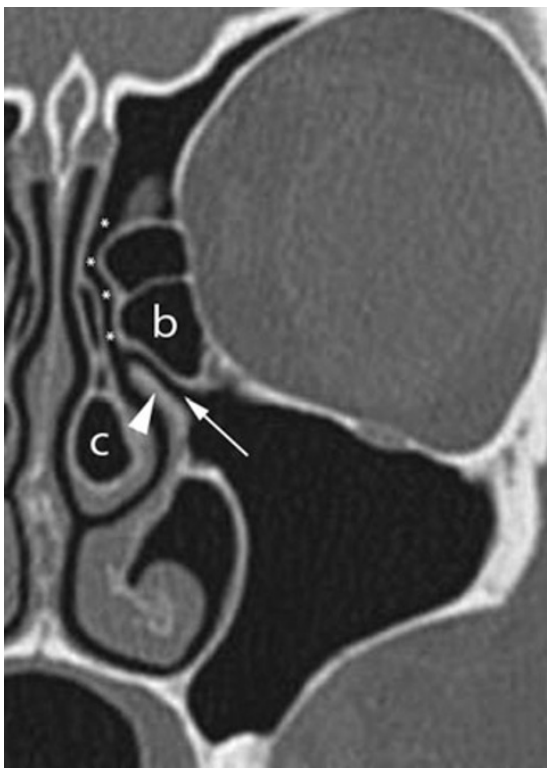

Fig. 2 Coronal MSCT. The ostiomeatal complex is the functional area in which the anterior ethmoid cells, and the maxillary and frontal sinus drain. It is composed of the middle turbinate (pneumatised in this case, $c$ ), the uncinate process (arrowhead), the ethmoid bulla $(b)$, the ethmoid infundibulum (arrow), and the frontal recess (asterisks) ethmoid) or on the middle turbinate will result in a frontal recess coursing lateral to the uncinate process and emptying into the ethmoid infundibulum; otherwise, if the superior insertion of the uncinate process is on the medial orbital wall, the frontal recess will run medial to the process, closer to the middle turbinate (Fig. 3). The sphenoethmoid recess is the drainage pathway for the sphenoid sinus and posterior ethmoid cells, and is easily seen on axial images as a short and thin channel arising from the anterior sphenoid sinus wall and coursing just medial to the nasal septum. On coronal and sagittal images, the sphenoethmoid recess is less clearly seen; on MSCT examinations, correct identification is improved by interactive navigation on 3D workstations (Fig. 4).

A factor that cannot be neglected: the anatomical variants

Overall, the number and frequency of anatomical variants is so high that at least one is to be expected in up to $60 \%$ of patients undergoing imaging [6]. Some are clinically irrelevant, some may be regarded as cofactors of chronic rhinosinusitis, as they narrow the drainage pathways for the paranasal sinuses; others need to be reported as a potential source of iatrogenic damage during endoscopic sinus surgery. In the anterior compartment, variants are mostly due to the extension of ethmoid pneumatisation to adjacent bone structures. Agger nasi cells, for example, are the

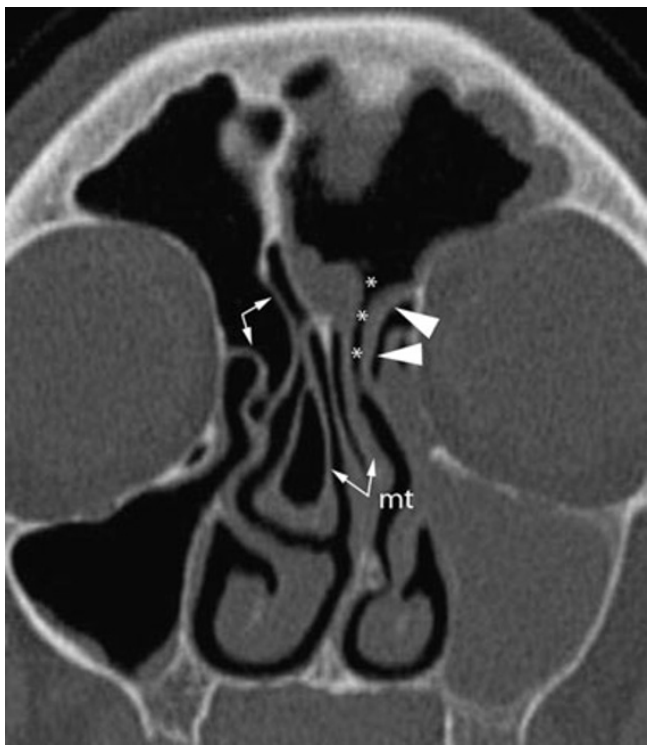

Fig. 3 Coronal oblique MPR reconstruction showing the variable cranial attachment of the uncinate process. On the left side, the uncinate process attaches laterally to the medial orbital wall (arrowheads), thus the frontal recess (asterisks) courses close to the middle turbinate $(m t)$. The ethmoid infundibulum is obstructed resulting in sinusitis with an infundibular pattern. On the right side, the uncinate process inserts on both the medial orbital wall and the skull base (arrows); the frontal recess (not visible) will drain into the middle meatus 

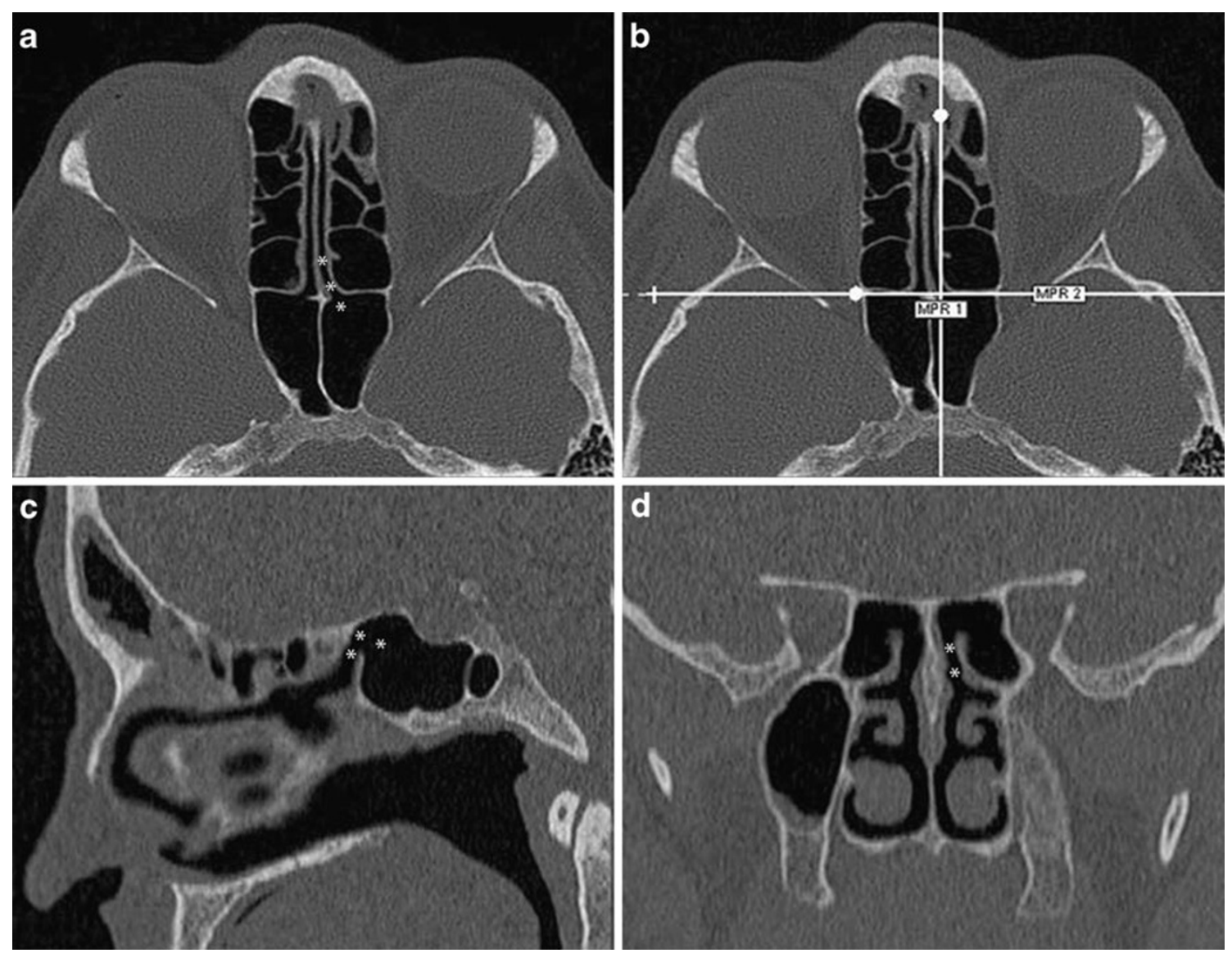

Fig. 4 The sphenoethmoid recess (asterisks) is generally well seen on the axial plane along the medial aspect of the anterior sphenoid sinus wall. Identification on the coronal and sagittal planes can be simplified navigating through the volume as shown in $\mathbf{b}$, $\mathbf{c}$ and $\mathbf{d}$

result of ethmoidal pneumatisation of the lacrimal bone; they are the most anterior ethmoidal cells found on standard coronal images, visible anterior to the ethmoid fovea and the crista galli. When large, these cells may narrow the frontal recess, as best displayed by sagittal reformations (Fig. 5). Infraorbital and supraorbital cells are the extension of ethmoid pneumatisation to the orbital floor or roof, respectively. The former, more commonly called Haller cells, may narrow the ethmoid infundibulum, whereas the relevance of the latter is more strictly related to the correct planning of endoscopic surgery. Being located just posterior to the frontal sinus, these supraorbital cells may be easily overlooked on the coronal plane; the axial and sagittal planes are far more accurate in the detection of these cells, which drain through an ostium located inferior and lateral to the frontal recess [5] (Fig. 6). Concha bullosa, i.e. pneumatisation of the middle turbinate, is very frequently associated with contralateral septal deviation, although the developmental correlation between the two is unclear [7]. Both the variants may restrict the ostiomeatal complex, however no statistically significant correlation was found between the presence of these variants and any sinus disease [7]. Bulla frontalis is a group of variants basically indicating air cells located cranial to agger nasi cells and extending towards the frontal sinus: they can be isolated and protruding (type III) or not (type I) (Fig. 7) in the frontal sinus, or they can be a chain of air cells (type II); finally, type IV relates to isolated cells into the frontal sinus [5]. The uncinate process itself may exhibit variants such as pneumatisation or medial bending of the tip. The most relevant variant of the uncinate process is hypoplasia, which results in occlusion of the ethmoid infundibulum; this is associated with hypoplasia of the maxillary sinus, and commonly also chronic maxillary inflammation [8] (Fig. 8). In the posterior compartment, the Onodi cell is by far the most dreaded variant for the surgeon; this is generally a rather huge posterior ethmoid cell, which expands on top or lateral to the sphenoid sinus. If overlooked on a presurgical image, it can increase the hazard of middle cranial fossa penetration during endoscopic surgery (Fig. 9). Similarly, the risk of iatrogenic damage may be amplified by other variants such as dehiscences and protrusions (Fig. 10). Dehiscences are more crucial when seen at the level of the ethmoid roof and medial orbital wall; their classification as either of posttraumatic or of congenital origin is debated as the apparently congenital ones might also be the result of a neglected 

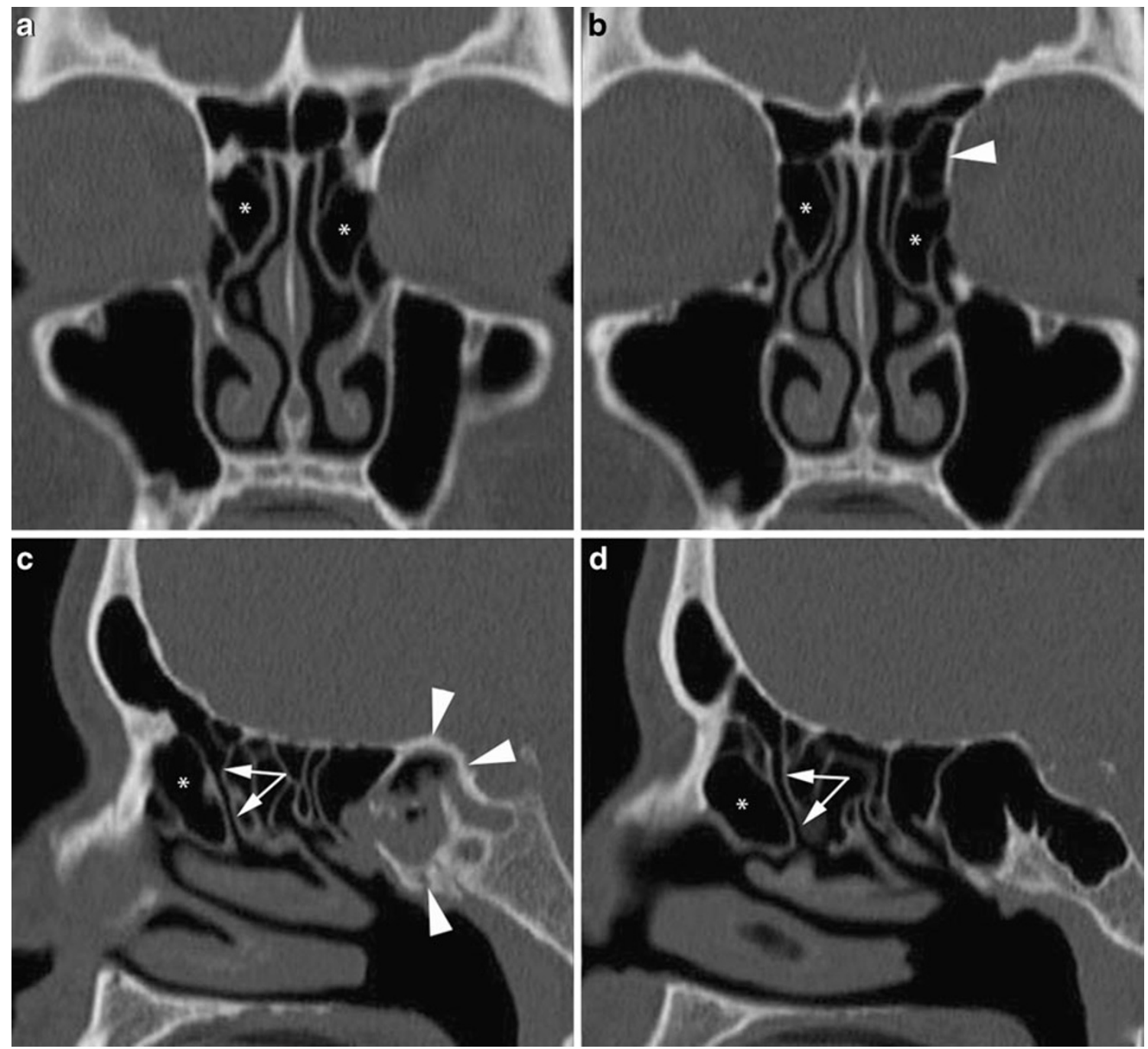

Fig. 5 MSCT coronal $(\mathbf{a}, \mathbf{b})$ and sagittal reformations obtained on the right (c) and left (d) sides. Bilateral agger nasi cells (asterisks) are visible on the coronal images, but sagittal reformations better display their relationships with the frontal recesses (arrows). A type I bulla

trauma [9]. Protrusions relate to bulging of the carotid canal, foramen rotundum, vidian canal, optic canal within an hyperpneumatised sphenoid sinus [10].

\section{Chronic rhinosinusitis and imaging: the survival kit}

The rationale for imaging of patients affected with chronic rhinosinusitis, simplified to the extreme, consists in demonstrating any impairment of mucus clearance through the aforementioned pathways, along with any anatomical variant that may either incite rhinosinusitis or raise the risks of endoscopic surgery. Given its superb detail in depicting the thinnest bone structures, MSCT is the most suitable technique for the task [3]; the inherent contrast displayed on bone algorithm reconstructions among bone, air and soft tissues allows the radiation dose to be decreased to a minimum, thus frontalis (arrowhead in b) can be seen on top of the left agger nasi cell. Inflammatory material with focal calcifications is retained within the right sphenoid sinus whose walls are densely sclerotic (arrowheads in c): chronic inflammation, possibly a fungus ball (see below)

allowing all information to be obtained with limited biological invasiveness.

MSCT reporting of the paranasal sinuses should be done in a centripetal fashion, thus moving from the centre, i.e. the nasal septum and the respective drainage pathways, to the periphery represented by all sinuses. Both soft-tissue and bone changes should be reported. Five patterns of rhinosinusitis, namely the infundibular, sphenoethmoidal, ostiomeatal and sporadic patterns as well as nasal polyposis are described [11, 12]. Sometimes several patterns are combined in the same patient.

The infundibular pattern relates to the obstruction of the ethmoid infundibulum by soft-tissue thickening, which results in impaired drainage of the maxillary sinus; this sinus is opacified by thickened mucosa, submucosal oedema and/or entrapped fluid secretions (Fig. 11). Similarly, obstruction of the sphenoethmoid recess will impair 


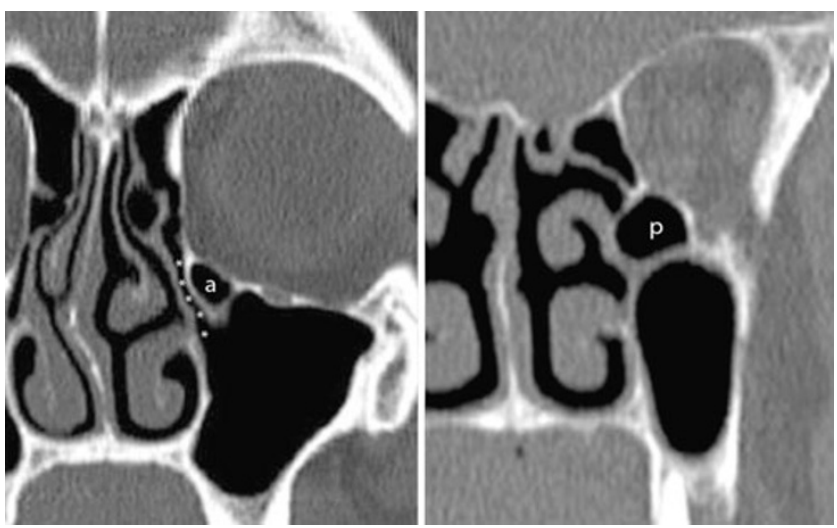

Fig. 6 Anterior $(a)$ and posterior $(p)$ infraorbital cells seen in two different patients; the former is strictly adjacent to the ethmoid infundibulum, the latter minimally displaces the orbital wall. The anterior one is also called a Haller cell

the drainage of the posterior ethmoid and sphenoid sinus, producing what is referred to as a sphenoethmoid pattern (Fig. 12). The ostiomeatal pattern is a more complex one, reflecting the higher complexity of this anatomical subunit, which, when blocked, simultaneously impairs mucus drainage from the anterior ethmoid cells and the maxillary and frontal sinus (Fig. 13). Nasal polyposis is the most extensive pattern, and nearly always occurs bilaterally. The mucosa investing the middle turbinate, the uncinate process and the ethmoid infundibulum are the most usual sites of origin of polyps. The hypertrophied, polypoid soft-tissue thickening tends to distort the adjacent bone structures and enlarge the ethmoid infundibulum, quite often invading the maxillary sinus. Such a growth pattern almost invariably produces ostiomeatal pattern rhinosinusitis; pansinusitis due to extension to the posterior ethmoid (and thus impairment of the sphenoethmoid recess) is similarly frequent (Fig. 14).

The sporadic pattern is a large box in which several different conditions are stored, such as isolated mucosal thickenings, retention cysts, antrochoanal polyp, silent sinus syndrome, odontogenic sinusitis and mucocele.

Isolated mucosal thickenings are incidentally found in a large number of MSCT performed for non-sinonasal pathological conditions. As a general rule, such mucosal thickening is unrelated to clinical symptoms, and when seen in the maxillary sinus and ethmoid cells, it does not need to be reported unless the mucosal thickness exceeds $4 \mathrm{~mm}$ and $2 \mathrm{~mm}$, respectively. On the other hand, the mucosal lining of the frontal and sphenoid sinuses should not be visible on MSCT under normal conditions [13].

Retention cysts are submucosal (pseudo-)cystic lesions that may have serous (fluid accumulation in the submucosa) or may be of a mucous nature (blockage of a submucosal mucus gland). At imaging, they display a convex shape and sharply demarcated borders, and are attached to a sinus wall; thus, they do not change with the patient's decubitus. They have little clinical relevance unless large enough to hinder mucus drainage (Fig. 15).

Antrochoanal polyp is a relatively easy diagnosis, based on the pattern of growth (from the maxillary sinus to the nasal fossa and farther to the choana) and nature (cystic appearance) of this generally isolated polypoid lesion. Though much rarer, spheno- and ethmoidochoanal variants are also reported [14, 15] (Fig. 16).

Silent sinus syndrome refers to an obstructed maxillary sinus, occupied by inflamed mucosa and secretions, which is shrunken with depression of the orbital floor causing exophthalmia. It is called silent sinus syndrome when clinically there is no clue as to the maxillary sinus disease, only being discovered on an imaging study. Differentiation
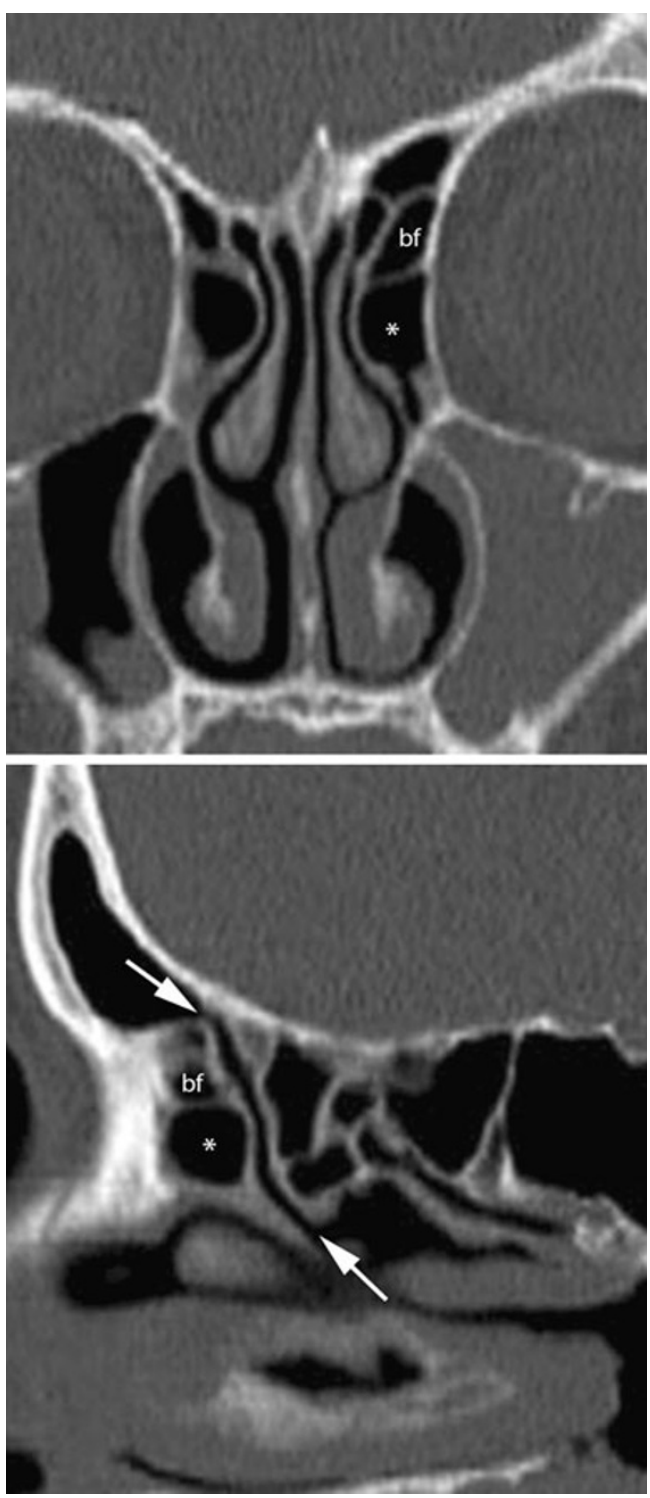

Fig. 7 Coronal and sagittal MSCT reformations showing type I bulla frontalis (bf), on top of an agger nasali cell (asterisk), and its relationships with the frontal recess (arrows), posteriorly 

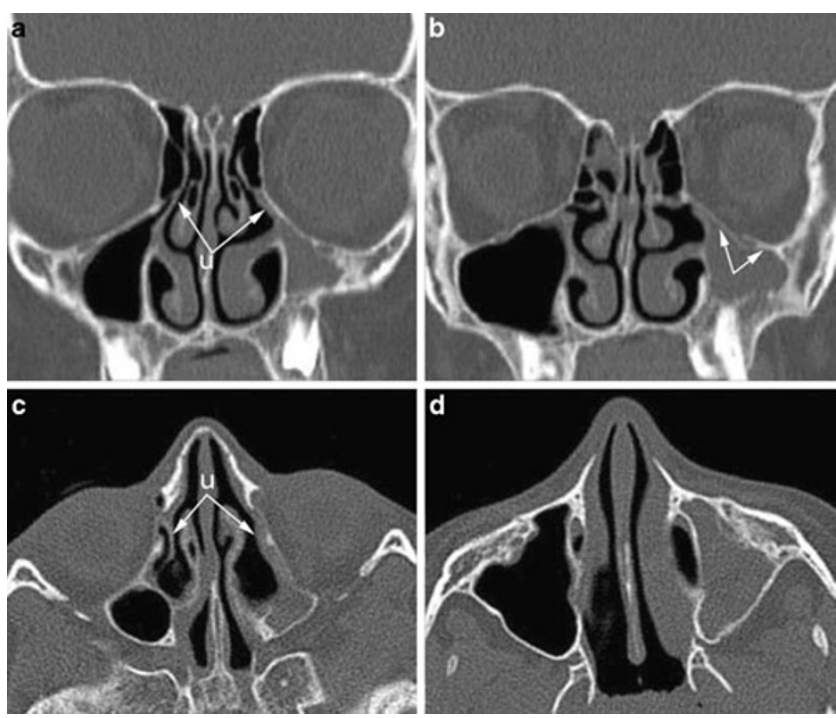

Fig. 8 Axial MSCT and coronal reconstructions of a patient suffering silent sinus syndrome. The left uncinate process $(u)$ is hypoplastic and tightly attached to the medial orbital wall (compare with the contralateral side), hindering maxillary sinus drainage. The sinus cavity is shrunk and the orbital floor is slightly depressed because of chronic hypopressure

of this entity from a congenitally hypoplastic maxillary sinus may be difficult. Interestingly, antrochoanal polyp and silent sinus syndrome share the same pathophysiological mechanism, i.e. maxillary sinus blockage. In antrochoanal polyp, an increased intrasinusal pressure (due to partial ostial obstruction with unidirectional flow of air through the ostium into the sinus) is the trigger to force the expulsion of an intramural cyst through an accessory ostium [16]. In silent sinus syndrome, conversely, complete sinus blockage and progressive resorption of air within the cavity leads to a pressure drop, orbital floor depression and sinus contraction [8] (Fig. 8).
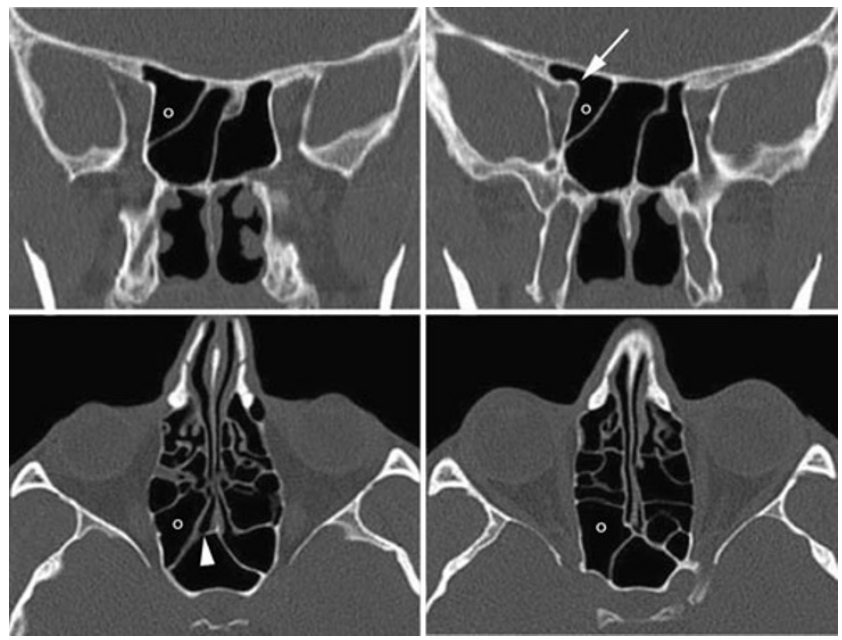

Fig. 9 A huge Onodi cell extends above and lateral to the right sphenoid sinus (arrowhead points to the sphenoethmoid recess), the arrow points to the protrusion of the optic canal within the air cell

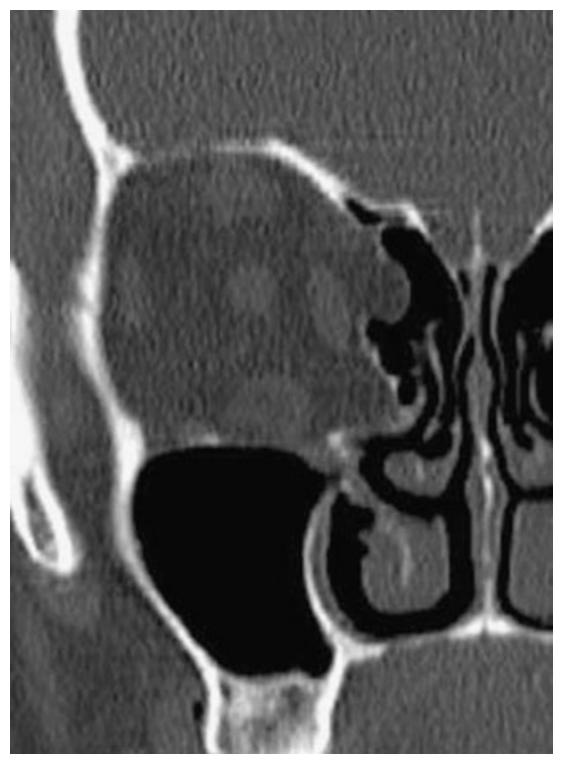

Fig. 10 Two focal bone dehiscences are seen along the medial orbital wall, through which a small amount of orbital fat tissue herniates. This condition increases the risks of endoscopic sinus surgery, particularly if extrinsic ocular muscles are entrapped in the bone gap

Odontogenic sinusitis (Fig. 17), is heralded by a combination of signs, namely isolated maxillary sinusitis, detection of periradicular inflammatory lesions, possibly with surrounding bone destruction, and sometimes retention within the sinus cavity of calcifications, or even hyperdense material, with a density similar to dental filling material. Intrasinus dental filling material may cause fungal surinfection. The differential diagnosis between dentogenic sinusitis and fungal infection (see below) may be difficult on imaging studies.

Finally, chronic sinus drainage obstruction may end up in mucocele formation: a mucocele is an epithelium-lined mucus collection completely filling a sinus cavity; while the secretions accumulate, pressure within the cavity increases, inducing sinus expansion and bone remodelling. Mucoceles

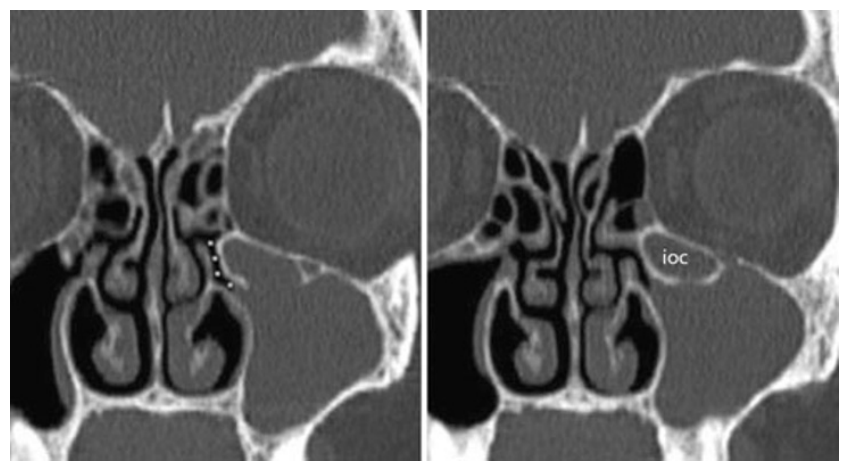

Fig. 11 Sinusitis with infundibular pattern: the most proximal part of the ethmoid infundibulum (asterisks) is obstructed by thickened mucosa, the maxillary sinus is completely opacified by inflammatory material. Although large, the infraorbital cell (ioc)does not narrow the drainage pathway 

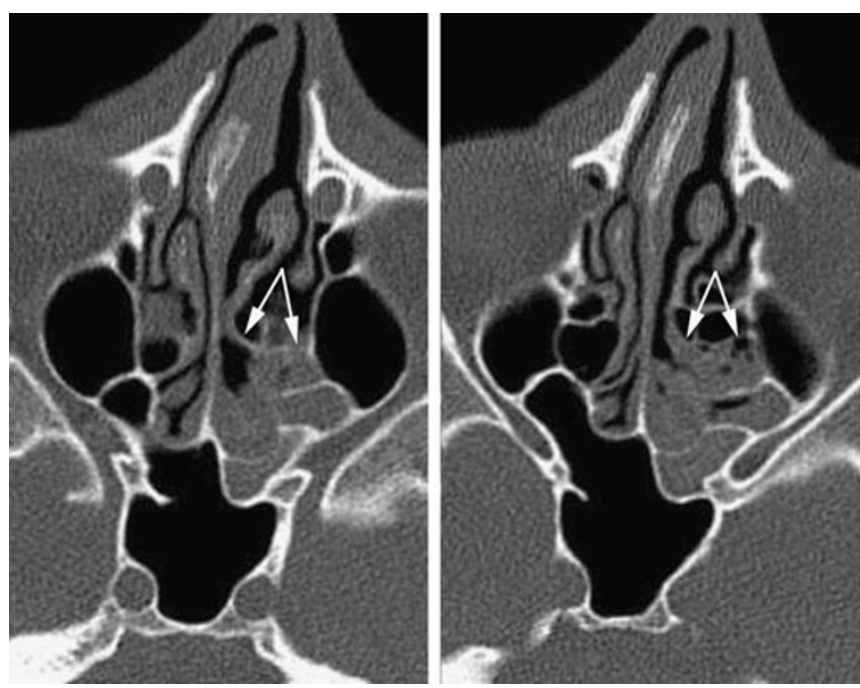

Fig. 12 Sinusitis with a sphenoethmoid pattern: the sphenoethmoid recess is obstructed by thickened mucosa (asterisks), both the small left sphenoid sinus and the posterior ethmoid cells are opacified. Note the

(Fig. 18) are more frequent in the fronto-ethmoid region but probably more dangerous in the sphenoid sinus, where sinus expansion may result in severe damage to the optic nerve.

The other side of the coin: bone changes

Bone remodelling is a broad definition that encompasses the whole spectrum of alterations that may accompany the aforementioned mucosal changes in chronic rhinosinusitis and nasal polyposis. As described by Giacchi et al. [17], bone remodelling is an adaptive process, in which osteoblasts and osteoclasts can be variably involved, that can be triggered by mechanical factors (pressure, in nasal polyposis and mucocele) as well as inflammatory mediators or infectious agents (bacterial invasion of periosteum and
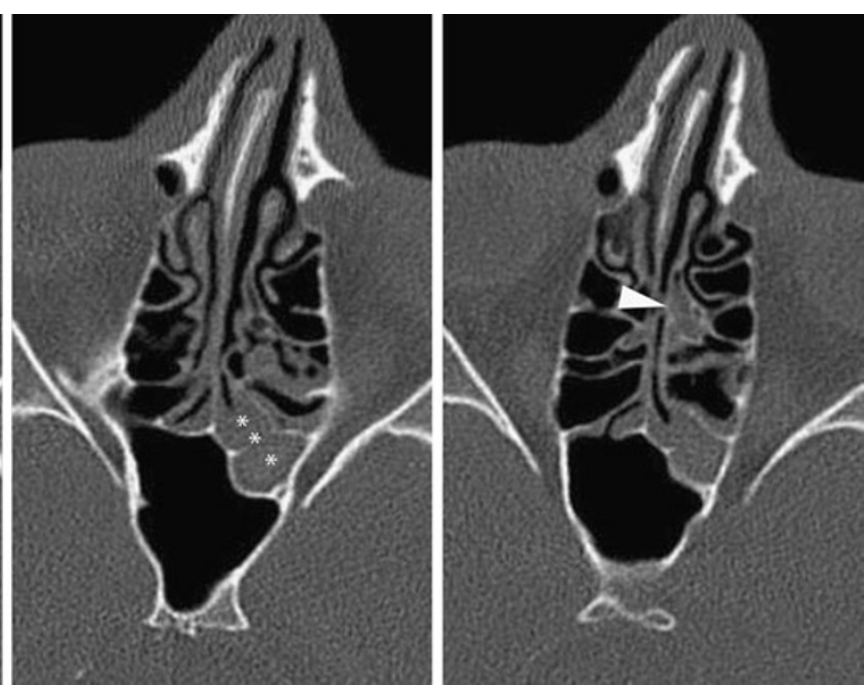

basal lamella (arrows) clearly demarcating the anterior ethmoid from the inflamed posterior ethmoid cells. Secretions are also retained within the pneumatised vertical lamella of the middle turbinate (arrowhead)

bone). The prevalence of osteoclastic activity provokes bone resorption and demineralisation; this is mostly seen in thin bone structures subject to chronic pressure. Thinning and displacement of ethmoid septa or the medial wall, as well as truncation of the middle turbinate are, for example, frequent findings in nasal polyposis; similarly, the expanded sinus walls of mucoceles are often thinned if not totally demineralised. On the other hand, osteoblastic activity manifests itself as thickening and sclerosis of bone (osteitis) [13], more typically encountered in thicker bone structures, such as the walls of the maxillary sinus and sphenoid sinus. As expected, all the described bone changes can be present simultaneously in the same patient, particularly if affected by nasal polyposis and fungal infections (see below) (Fig. 19).
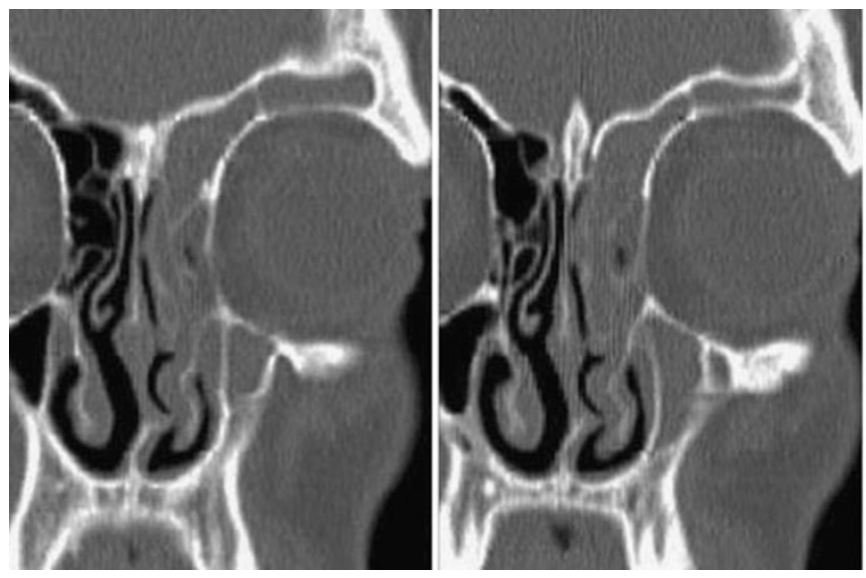

Fig. 13 Ostiomeatal complex pattern: the middle meatus (asterisk) and anterior ethmoid cells are occupied by tissue, the medial orbital wall appears slightly displaced (arrows). Mucus drainage from the

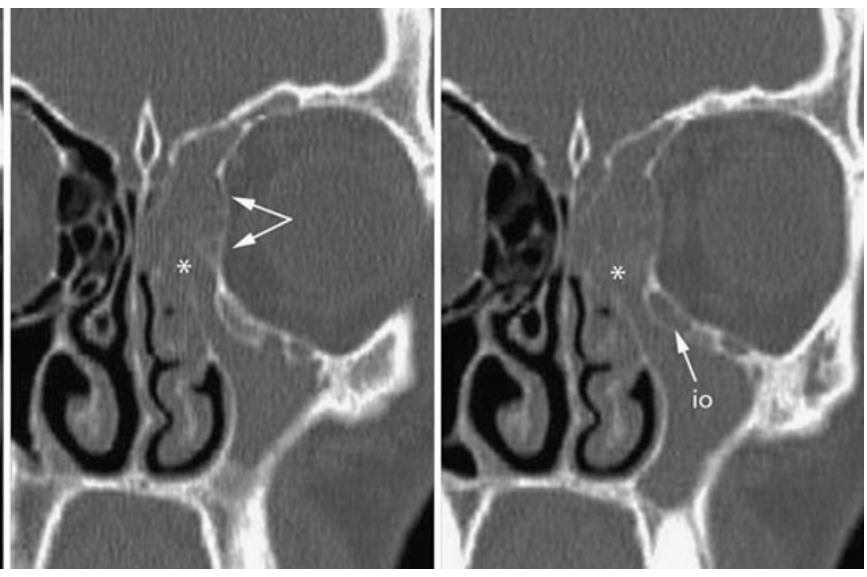

ethmoid infundibulum and frontal recess is simultaneously hindered producing frontal and maxillary sinusitis (io infraorbital cell) 

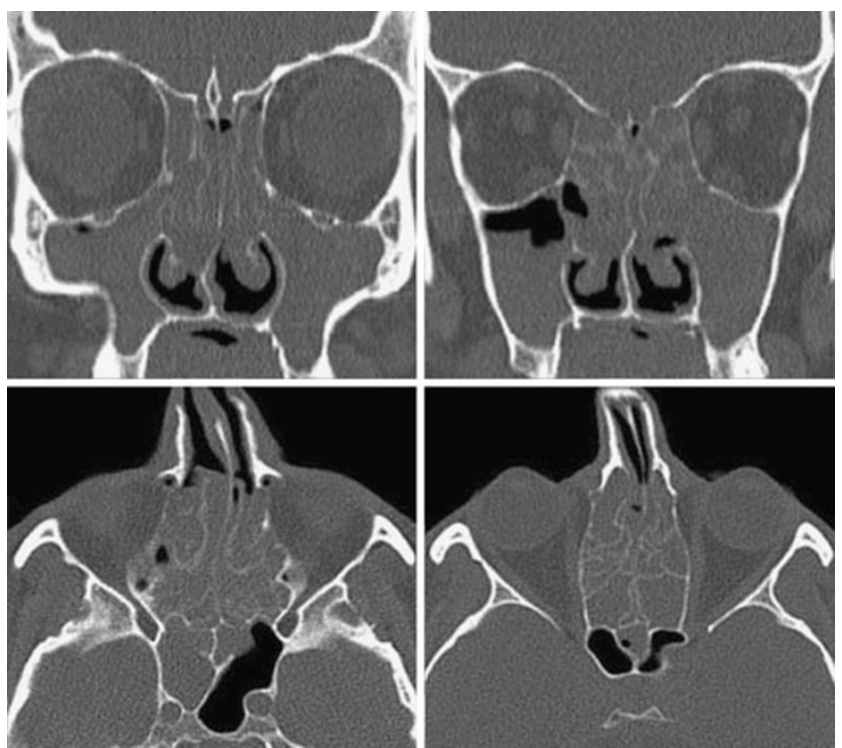

Fig. 14 Nasal polyposis: diffuse bilateral thickening of the mucosa investing the middle meati, the middle turbinate, and the anterior and posterior ethmoid cells. The turbinates and ethmoid labyrinth are distorted and partially decalcified. Retained secretion can be seen within the blocked maxillary and sphenoid sinuses

A common dilemma: how to differentiate polyps from neoplasms?

Some of the imaging patterns of chronic rhinosinusitis already described (such as the ostiomeatal pattern and mucocele) can also be encountered as indirect signs of the presence of a neoplasm - either benign or malignant. Furthermore, extensive nasal polyposis may completely obstruct sinonasal

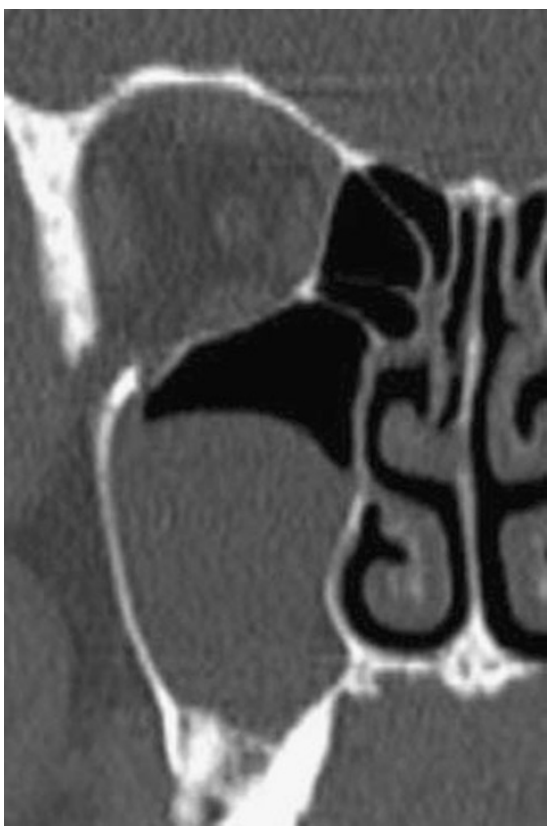

Fig. 15 A retention cyst, displaying typical smooth and convex borders, partially fills the maxillary sinus cavity
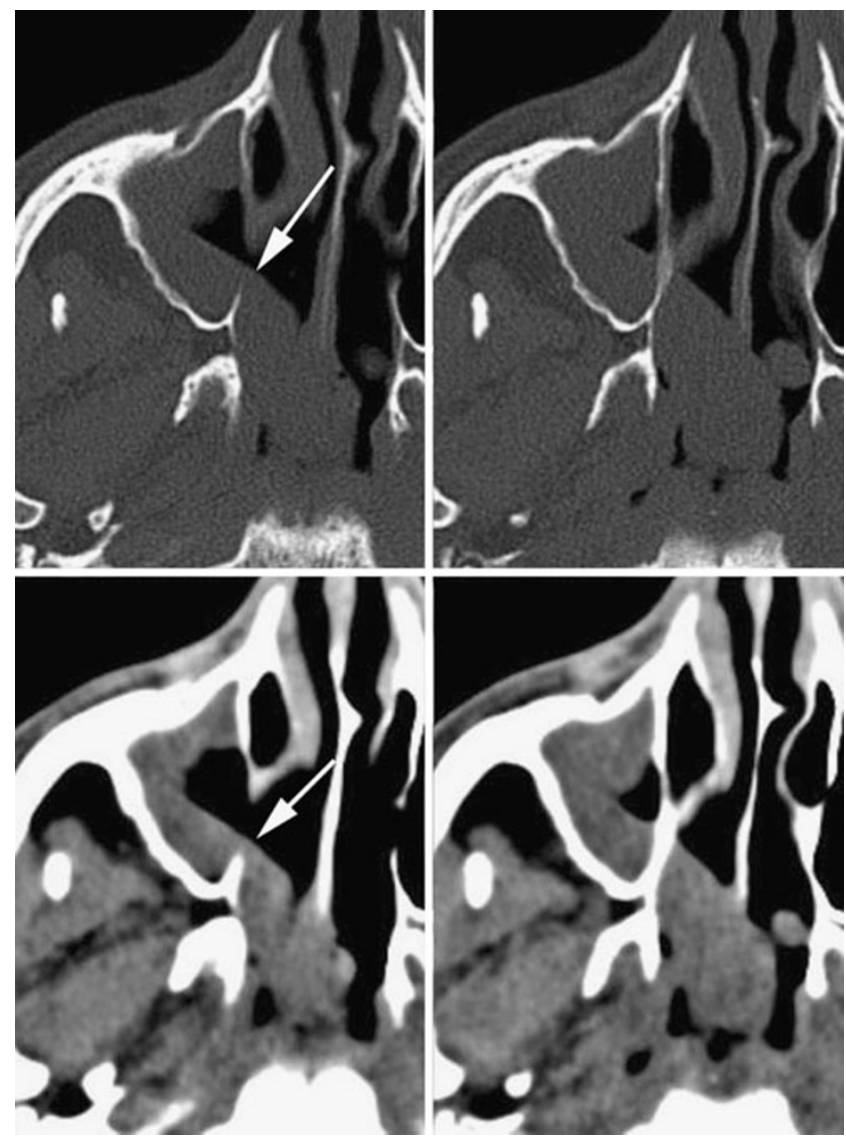

Fig. 16 Antrochoanal polyp: the polypoid lesion arises from the right maxillary sinus, and extends through an accessory ostium (arrows) into the nasal fossa, reaching posteriorly the nasopharynx through the choana
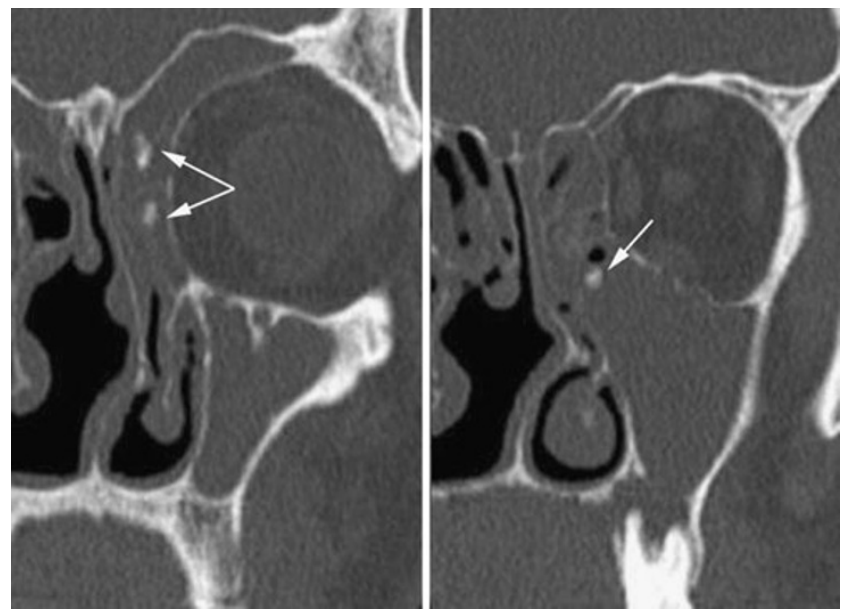

Fig. 17 Odontogenic sinusitis. A large area of bone resorption is seen in the alveolar ridge, around the root of a molar tooth; the floor of the maxillary sinus is interrupted, the sinus filled by inflammatory material. The small calcifications found along the ethmoid infundibulum and in the anterior ethmoid (arrows) were proven to be bone fragments, possibly transported by mucociliary clearance 

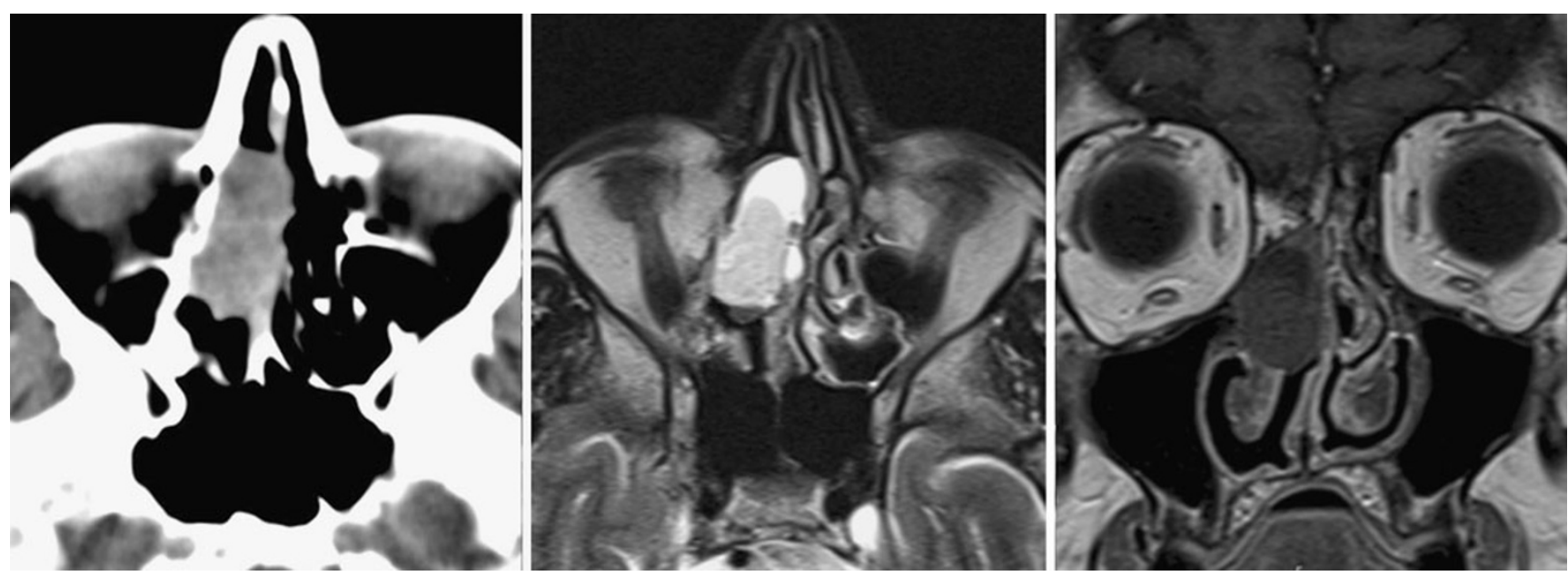

Fig. 18 The right middle turbinate is swollen by a sharply defined lesion exhibiting spontaneously high density on MSCT, and showing different fluid components on MRI. Absence of solid, enhancing areas confirms mucocele within a pneumatised middle turbinate

cavities, severely distorting the normal anatomy. Patients examined for rhinosinusitis undergo imaging applying a standard MSCT protocol, without contrast agent injection, and using bone algorithm reconstructions alone. As a consequence, the major concern for radiologists (particularly those not routinely involved in sinonasal imaging) is how to safely rule out a neoplasm harboured amid inflammatory
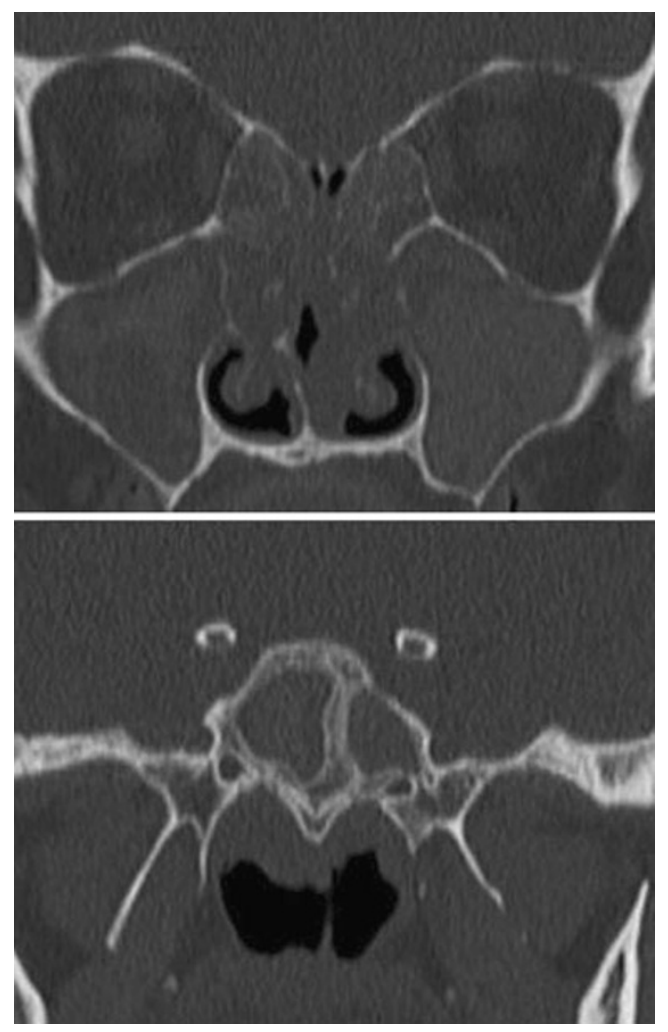

Fig. 19 Demineralisation and distortion of thin bony laminae (middle turbinates and ethmoid labyrinth) and sclerosis of thicker bone structures (sphenoid sinus) are present simultaneously in a patient with diffuse nasal polyposis changes. Some landmarks may be of help: chronic rhinosinusitis (and nasal polyposis) are much more commonly bilateral. Whenever a ostiomeatal pattern is seen as unilateral disease, the presence of a neoplasm in the middle meatus should be considered, and endoscopic assessment of the region should be prompted. Neoplastic lesions, even when benign, tend to behave more aggressively towards bone, causing more pronounced displacement, erosion and destruction [18]. In chronic rhinosinutis and nasal polyposis bone is remodelled, distorted, demineralised but, as a general rule, not frag-

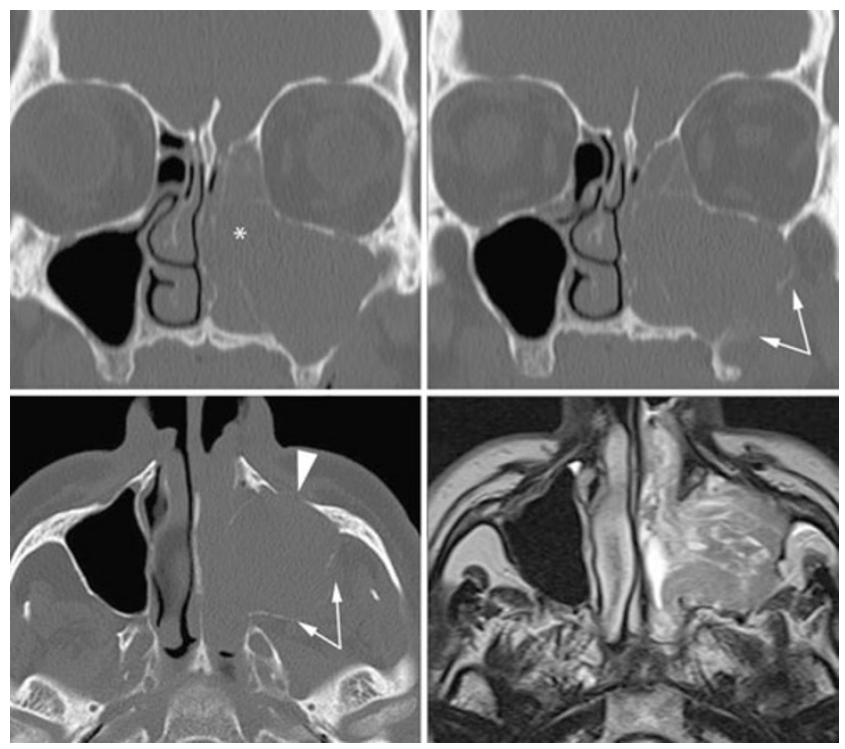

Fig. 20 The left ostiomeatal complex is occupied by solid tissue, the anterior ethmoid cells, the maxillary and frontal sinus are completely opacified. The absence of inflammatory changes on the right side as well as the displacement and destruction of the anterior (arrowheadss) and the posterior (arrows) maxillary sinus wall suggests the presence of a neoplasm. Actually, MRI shows a mass arising from the maxillary sinus and protruding into the nasal fossa, histologically proven as ameloblastoma 

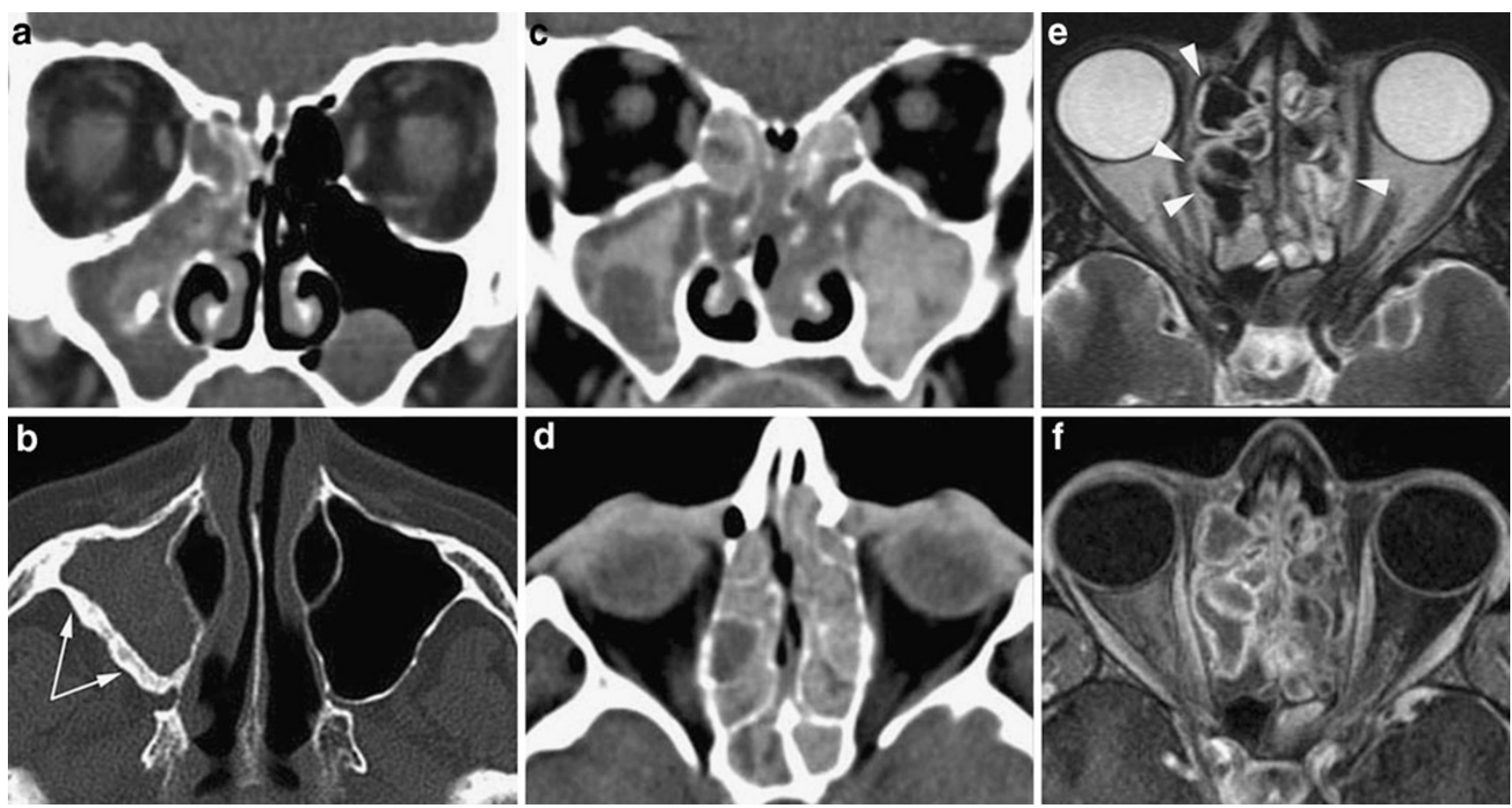

Fig. 21 Non-invasive fungal rhinosinusitis. a, b The maxillary sinus is filled, at the periphery, by hypodense thickened mucosa and contains, in the centre, a calcification; dense sclerosis of the posterolateral wall secondary to chronic inflammation (arrows). These findings are consistent with a fungus ball. $\mathbf{c}, \mathbf{d}$ Chronic rhinosinusitis with polypoid thickening of the mucosa and hyperdense material

mented. Mucocele is emblematic: frequently the line of demarcation between demineralised and normal bone is represented by a blunt but sharp border, whereas in neoplasms the border is ill-defined and spiculated. Density measurements are not of great help, neither for the
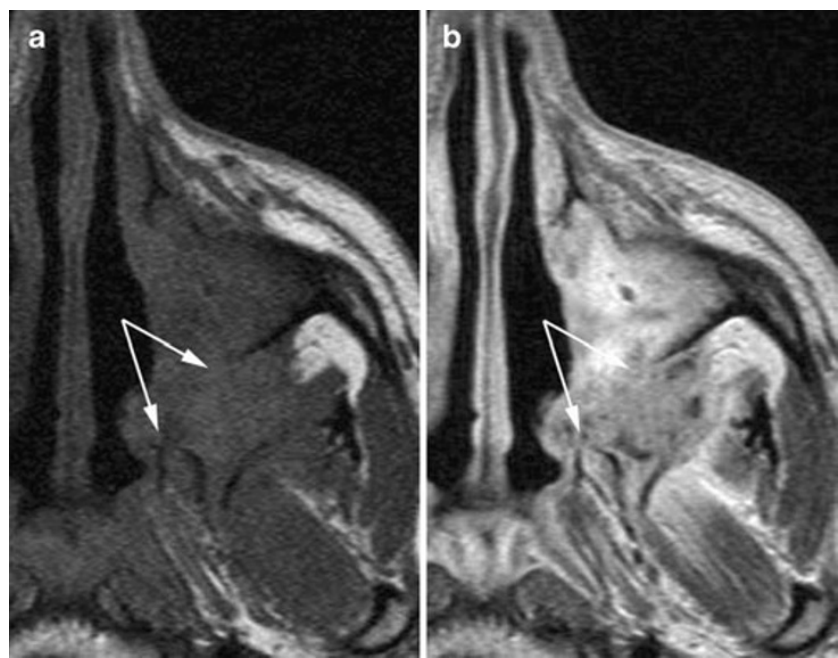

Fig. 22 MRI SE T1 before (left) and after (right) contrast application. Chronic invasive mycosis invading the maxillary sinus mucosa, destroying the pterygoid plates and posterior maxillary sinus wall (arrows), and invading the infratemporal fossa scattered in all sinus cavities: this pattern suggests allergic fungal rhinosinusitis. e, f On MRI eosinophilic mucin displays T2 hypointense signal comparable with air: the $\mathrm{T} 1$ intermediate signal along with bone remodelling and sinus expansion (arrowheads) help to make the diagnosis of allergic fungal rhinosinusitis

differentiation between tumour and polyp (both are within the solid range of densities) nor to discriminate tumour from mucocele (which may exhibit high density if secretions are desiccated). In some cases, MRI may add information (polyps are generally more $\mathrm{T} 2$ hyperintense than most malignant tumours; inverted papilloma, the most common benign nasosinusal tumour, may display the almost pathognomonic cerebriform pattern). However, the bottom line is that in any unclear case an endoscopic examination should be performed, and a biopsy obtained (Fig. 20).

\section{Fungal infection}

Fungal infection is rather common, given the ubiquitous presence of fungal agents in the environment and the high frequency of colonisation of sinonasal mucosa [19]; the role of fungi in promoting chronic rhinosinusitis has been suggested. Fungal infections may be classified as either non-invasive or invasive forms, according to the absence or presence of invasion of mucosa, submucosa, bone and vessels by hyphae [20].

The non-invasive form occurs in immunocompetent subjects and may further be classified as fungus ball and eosinophilic rhinosinusitis; these forms are seen in patients with chronic rhinosinusitis, and are non-responsive to 
medical and/or surgical treatment [21]. Eosinophilic rhinosinusitis is also called allergic fungal rhinosinusitis. On MSCT, non-invasive fungal infection is suspected whenever spontaneously hyperdense material is detected within the sinus cavities.

In the case of a fungus ball, such hyperdensity is due to a high content of heavy metals in the hyphae, but small calcifications can also be seen. Maxillary fungal sinusitis may also be caused by the presence of intrasinusal dental filling material, which appears extremely hyperdense. In $80 \%$ of cases, the disease is unilateral and located in the maxillary sinus [22] (Fig. 21). In eosinophilic rhinosinusitis, besides fungal hyphae, the accumulation of dense eosinophilic mucin may account for the detection of sinus hyperdensities, which are scattered in multiple sinus cavities, uni- or bilaterally. MRI can be misleading in both conditions, because heavy metal and calcium, on the one hand, and the tight packing of fungal material within sinuses, on the other hand, produce very hypointense signal which, particularly on $\mathrm{T} 2$ sequences, can be as low as the signal void of air (Fig. 21).

Invasive fungal infection can be divided into an acute invasive form and a chronic invasive form, and both usually occur in immunocompromised subjects (diabetes mellitus with or without ketoacidosis, organ transplantation, chemotherapy, haematological diseases, HIV infection); the chronic invasive form has also been reported in immunocompetent hosts. The clinical presentation of invasive fungal infection includes fever, headache and epistaxis. Sinus hyperdensities are not common in invasive mycoses, bone destruction with invasion of adjacent anatomical structures (orbit, skull base, cavernous sinus, pterygopalatine fossa, periantral fat tissue) are the most significant imaging findings in both forms. Whilst the differential diagnosis between invasive and non-invasive forms is rather straightforward, the discrimination between acute invasive and chronic invasive is very difficult at imaging; this differentiation is mainly based on the clinical setting, as the acute invasive form is rapidly progressive and bears a dismal short-term prognosis (up to $50-80 \%$ mortality). Although MSCT equipment is more readily accessible in nearly every institution, invasive mycoses highly benefit from the high contrast resolution of MRI to provide thorough assessment of intracranial and cavernous sinus involvement (Fig. 22).

\section{Conclusion}

Interpretation of the MSCT examinations of patients affected by chronic rhinosinusitis should always be aimed at answering the key questions asked by clinicians. Assessment of location and extent of the disease, along with drainage pathway impairment, contributes to selecting candidates for surgical treatment. Detailed reporting on anatomical variants allows the best surgical approach to be identified and the risk of iatrogenic complications to be decreased. Finally, accurate evaluation of any suspect MSCT findings helps to identify those patients in whom chronic rhinosinusitis is the secondary effect of a neoplasm obstructing the sinus drainage pathways.

\section{References}

1. Anand VK (2004) Epidemiology and economic impact of rhinosinusitis. Ann Otol Rhinol Laryngol Suppl 193:3-5

2. Osguthorpe JD (2001) Adult rhinosinusitis: diagnosis and management. Am Fam Physician 63(1):69-76

3. Momeni AK, Roberts CC, Chew FS (2007) Imaging of chronic and exotic sinonasal disease: review. AJR Am J Roentgenol 189: S35-S45

4. Landsberg R, Friedman M (2001) A computer-assisted anatomical study of the nasofrontal region. Laryngoscope 111(12):2125-2130

5. Lee WT, Kuhn FA, Citardi MJ (2004) 3D computed tomographic analysis of frontal recess anatomy in patients without frontal sinusitis. Otolaryngol Head Neck Surg 131(3):164-173

6. Lehmann P, Bouaziz R, Page C, Warim M, Saliou G, Deschepper B, Strunski V, Deramond H (2009) Sinonasal cavities: CT imaging features of anatomical variants and surgical risk. J Radiol 90(1 pt 1):21-30

7. Stallman JS, Lobo JN, Som PM (2004) The incidence of concha bullosa and its relationship to nasal septal deviation and paranasal sinus disease. AJNR Am J Neuroradiol 25:1613-1618

8. Lawson W, Patel ZM, Lin FY (2008) The development and pathologic processes that influence maxillary sinus pneumatization. Anat Rec 291:1554-1563

9. Champsaur P, Pascal T, Vidal V, Gaubert JY, Bartoli JM, Moulin G (2003) Radioanatomie des sinus de la face. J Radiol 84:885-900

10. Marsot-Dupuch K, Gentry E (2003) Les variants anatomiques des sinus de la face. J Radiol 84:357-367

11. Sonkens JW, Harnsberger HR, Blanch GM, Babbel RW, Hunt S (1991) The impact of screening sinus CT on the planning of functional endoscopic sinus surgery. Otolaryngol Head Neck Surg 105(6):802-813

12. Babbel RW, Harnsberger HR, Sonkens J, Hunt S (1992) Recurring patterns of inflammatory sinonasal disease demonstrated on screening sinus CT. AJNR Am J Neuroradiol 13(3):903-912

13. Eggesbø HB (2006) Radiological imaging of inflammatory lesions in the nasal cavity and paranasal sinuses. Eur Radiol 16(4):872-888

14. Bist SS, Bisht M, Kumar R, Varshney S (2007) Sphenochoanal polyp: an endoscopic view. Ear Nose Throat J 86(1):19-20

15. Virós Porcuna D, Montserrat Gili JR, Gras Cabrerizo JR, López Vilas M, Pujol Olmo A (2008) Unilateral benign choanal polyp: review of 51 patients. Acta Otorrinolaringol Esp 59(2):52-56

16. Frosini P, Picarella G, De Campora E (2009) Antrochoanal polyp: analysis of 200 cases. Acta Otorhinolaryngol Ital 29:21-26

17. Giacchi RJ, Lebowitz RA, Yee HT, Light JP, Jacobs JB (2001) Histopathologic evaluation of the ethmoid bone in chronic sinusitis. Am J Rhinol 15(3):193-197

18. Dammann F, Pereira P, Laniado M, Plinkert P, Löwenheim H, Claussen CD (1999) Inverted papilloma of the nasal cavity and the paranasal sinuses: using CT for primary diagnosis and followup. AJR Am J Roentgenol 172(2):543-548 
19. Aribandi M, McCoy VA, Bazan C 3rd (2007) Imaging features of invasive and noninvasive fungal sinusitis: a review. Radiographics 27(5):1283-1296

20. De Shazo RD (1998) Fungal sinusitis. Am J Med Sci 316(1):39-45

21. Mukherji SK, Figueroa RE, Ginsberg LE, Zeifer BA, Marple BF, Alley JG, Cooper LL, Nemzek WR, Yousem DM, Jones KR,
Kupferberg SB, Castillo M (1998) Allergic fungal sinusitis: CT findings. Radiology 207:417-422, 35(4):500-508

22. Farina D, Tomenzoli D, Borghesi A, Lombardi D (2005) Inflammatory lesions. In: Maroldi R, Nicolai P (eds) Imaging in treatment planning for sinonasal diseases. Springer, Berlin Heidelberg New York, pp 59-92 